\title{
Sons nas nuvens: sobre o lugar do fônico no \\ Curso de Linguística Geral
}

\author{
Alena Ciulla* \\ Luiza Milano**
}

\section{Resumo}

Neste artigo, partimos de uma leitura do Curso de Linguística Geral, com o apoio de uma ferramenta automática. Por meio de uma perspectiva computacional, nossa proposta é a de simular uma leitura isenta, na medida do possível, dessa importante obra, cujas interpretações, na maior parte das vezes, são vinculadas a tradições já estabelecidas pelos estudos clássicos. Contudo, esse exercício de objetividade - ou de afastamento das leituras canônicas - permite-nos apenas formular hipóteses sobre alguns aspectos da interpretação do texto. É preciso sempre voltar ao texto e ao nosso papel de leitores da obra, investigando a fundo cada uma dessas hipóteses. Conforme os resultados em nuvens que a ferramenta proporciona, os termos mais relevantes do $C L G$ são relacionados a um tema minimizado pela maior parte dos estudos saussurianos: o sistema fônico das línguas. Nosso intuito, então, foi o de estabelecer uma conexão entre esse resultado, que aponta para uma grande importân- cia do fônico nas línguas, e o que se pode depreender da obra do mestre genebrino.

Palavras-chave: Fônico. Curso de Linguística Geral. Ferdinand de Saussure.

\section{Introdução}

Nas leituras canônicas do clássico livro Curso de Linguística Geral (doravante, $C L G$ ), predomina a análise da obra a partir de eixos: pela ordem de apresentação (Introdução, Primeira Parte, Segunda Parte etc.), pela seleção

\footnotetext{
Professora do Departamento de Letras Clássicas e Vernáculas da Universidade Federal do Rio Grande do Sul. Professora do Programa de Pós-graduação em Letras da mesma Universidade. E-mail: alenacs@gmail.com

** Professora do Departamento de Letras Clássicas e Vernáculas da Universidade Federal do Rio Grande do Sul. Professora e orientadora do Programa de Pós-graduação em Letras da mesma Universidade. E-mail: luizamilanos@gmail.com
}

Data de submissão: set. 2017 - Data de aceite: out. 2017 http://dx.doi.org/10.5335/rdes.v13i3.7392 
de conceitos-chave (objeto, signo, valor etc.), pela interpretação de conjuntos temáticos (as ditas "dicotomias"), pelo percurso epistemológico suposto (leituras não lineares da obra). Como se pode ver, nesses cem anos de publicação do $C L G$, múltiplas formas de interpretação do legado do mestre genebrino surgiram baseadas em algum dos critérios elencados anteriormente. O presente trabalho parte de outro ponto de vista: propomos uma leitura do $C L G$, por intermédio do apoio de um aparato tecnológico - a ferramenta computacional ExATOlp - Extrator Automático de Termos e Ontologias da Língua Portuguesa (LOPES, 2012), ${ }^{1}$ que nos oferece um método estatístico/ linguístico-computacional, para elencar e hierarquizar termos importantes em um texto ou corpus. Ressaltamos que a ferramenta computacional utilizada é por nós pensada como um instrumento auxiliar, no sentido de propor uma leitura a partir de diferente perspectiva.

Por meio da metáfora da exploração de um terreno já conhecido, buscamos deslocar o olhar. Tínhamos uma cartografia de antemão, o valioso $C L G$ e diários de bordo de outros exploradores, orientações geográficas sobre altitude, latitude e relevo. No entanto, queríamos experimentar fazer uma trilha, sugerindo abrir mão do roteiro de viagem pré-estabelecido pelos famosos desbravadores. Resolvemos, então, investir no desafio de operar com um drone ${ }^{2}$. Arriscamos olhar de cima e ver a paisagem com suas irregularidades, trilhas, conexões, ângulos.
Não obstante, levamos em consideração a diversidade de registros já traçados, eles foram importantes documentos para estudo prévio do terreno. Sabemos, contudo, que corremos riscos, sim. Nesse sobrevoo que ora empreendemos, pretendemos apenas apontar as saliências encontradas. Isso não gera por si a interpretação. Sempre será preciso voltar ao texto, ao mapa.

Para situar o leitor, explicitaremos a origem de nossa empreitada. Frente à curiosa informação de que tínhamos à disposição uma ferramenta computacional capaz de fazer um levantamento terminológico de ocorrências, a partir de nuvens estatísticas (cf. podem ser vistas na seção 3), ficamos tentadas a submeter a obra que nos é tão cara a um "teste de saliência”. A ferramenta simula uma "leitura objetiva", considerando o todo do texto do $C L G$, sem levar em conta o conhecimento a respeito da obra, ou as distintas interpretações dessa, e aplica uma investigação, de modo panorâmico, sobre a relevância terminológica do ponto de vista estatístico e matemático. Partimos, assim, de uma oportunidade de olhar para o $C L G$ de forma isenta - pelo menos no que diz respeito às tradições dos estudos da obra -, pela simples evidência trazida à tona instrumentalmente.

Nossa pergunta é: o que esses dados estatísticos nos dizem acerca daquilo que é mais ocorrente no Curso de Linguística Geral? Essa busca, apoiada em aparato tecnológico, permitiu-nos configurar a 
hipótese ficcional de um leitor não afetado pela história da linguística (incluindo paixões e repulsas ou negação) nesses últimos cem anos. Sabemos que é um árduo esforço tentar deixar em suspenso os efeitos de uma herança. No entanto, nossa intenção aqui será controlar um tanto das interpretações teóricas para deixar brotar uma leitura não contaminada do texto do $C L G$. O leitor perceberá que, após um exercício de objetividade (cf. seção 3), realizaremos inevitavelmente a leitura que nos é possível desde o nosso lugar de intérpretes do legado do genebrino (cf. seção 4).

No presente trabalho, trazemos, então, resultados da aproximação à totalidade do $C L G$ em português brasileiro, a partir do processamento pelo ExATOlp. A expectativa era a de que os resultados da ferramenta computacional apontassem para a maior relevância de conceitos mais frequentemente associados ao ensino do legado saussuriano, como língua, fala, significado, significante, signo, sincronia, diacronia, relações associativas e relações sintagmáticas. No entanto, o panorama geral do conteúdo lexical que o ExATOlp trouxe à tona foi outro. Não que não tenham aparecido, nas listas geradas pela ferramenta, termos relacionados a esses conceitos, sem dúvida importantes no $C L G$. A questão é que as listas salientaram, sobretudo, termos relacionados aos aspectos fônicos da língua - assunto nem sempre considerado como relevante no $C L G$.
Antes de apresentarmos nossas análises, é preciso agregar uma importante ponderação no que diz respeito à contextualização da noção de autoria do $C L G$. Não nos parece demasiado lembrar que esta é uma obra peculiar também pela sua concepção, pois que foi escrito com base em notas de alunos e por editores (colegas) que não o próprio Saussure. Soma-se a essa múltipla interpretação de que foi resultado o $C L G$, o fato de trabalharmos com uma tradução do texto, de que, é sabido, decorrem novas interpretações e releituras. Por isso, muito do que se atribui ao pensamento de Ferdinand de Saussure é o reflexo de diferentes pontos de vista e da escolha dos termos para descrevê-los.

Ainda assim, é curioso o fato de que a ferramenta que nos serviu de auxílio tenha colocado em evidência, conforme explanaremos abaixo, um tema do $C L G$ que vem sendo minimizado pela maior parte dos estudos saussurianos (não apenas em português ou no Brasil). Em outras palavras, os pressupostos difundidos da teoria, das principais interpretações que foram sendo feitas da obra ao longo do tempo, não necessariamente confirmam os de maior recorrência e/ou relevância via ferramenta. É justamente a surpresa frente a esse achado que gerou o presente estudo. 


\section{Procedimentos metodológicos: sobre a ferramenta}

O ExATOlp é uma ferramenta computacional que é aplicável a qualquer domínio, dirigida a textos escritos em português, conforme Lopes (2012). Partindo de um processo com base linguística e estatística, a principal vantagem dessa ferramenta é que ela fornece, dentre diversas funcionalidades, uma lista dos sintagmas nominais (SN) candidatos a termos mais relevantes de um corpus, considerando outros corpora como elementos de contraste ao corpus de estudo. Esse processo pode auxiliar a rápida identificação de temas e termos recorrentes e de maior especificidade para o corpus em questão, especialmente tratando-se de grandes volumes de texto. Os resultados são apresentados em listas de diversos tipos, as quais podem, então, ser analisadas como um apanhado geral e em detalhe.

A ferramenta ExATOlp implementa um conjunto de técnicas proposto por Lopes (2012) e representa o estado da arte em extração de termos a partir de corpo$r a$ em língua portuguesa. Diz-se de base linguística, porque a ferramenta elenca, por meio de heurísticas, todos os SN do corpus, aos quais são atribuídos pesos, maiores quando na função de sujeito e objeto. Assim, são hierarquizados os SN que apresentam maior probabilidade de serem candidatos a termo do corpus em questão. A partir daí é aplicado um cálculo (chamado índice de relevância) que leva em conta a frequência, o peso e especificidade de cada SN extraído, sempre em relação aos corpora ou ao corpus de contraste. $\mathrm{O}$ contraste é feito comparando-se os índices de frequência dos SN do corpus de estudo com os que são encontrados em outros corpora - entendido, aqui, que todos os SN, tanto do corpus de estudo como os dos corpora de contraste, foram previamente selecionados pelo sistema do ExATOlp entre os que têm maior chance de desempenhar um papel de termo, pela sua posição sintática (de sujeito ou objeto). Explicando o algoritmo estatístico, grosso modo, podemos dizer que, quando um dos SN ao qual foi atribuído peso maior (pela função sintática e, portanto, potencial candidato a termo) é bastante frequente no corpus de estudo, mas também nos corpora de contraste, isso significa que não é um bom candidato a termo, pois não é específico da área de domínio do corpus em estudo. Por outro lado, se ele aparece pouco ou nem aparece nos corpora de contraste, mas aparece no corpus de estudo, é um bom candidato a termo.

Portanto, o resultado que a ferramenta traz é sempre uma comparação do corpus de estudo em relação a um corpus de contraste, e os termos que aparecem como específicos do corpus de estudo são sugeridos como principais candidatos a termos.

A seguir, um diagrama que ilustra, de forma esquemática, essa sequência de atividades de preparação e processamento dos corpora pelo ExATOlp. 
Figura 1 - Diagrama do processamento de corpora implementado pela ferramenta ExATOlp

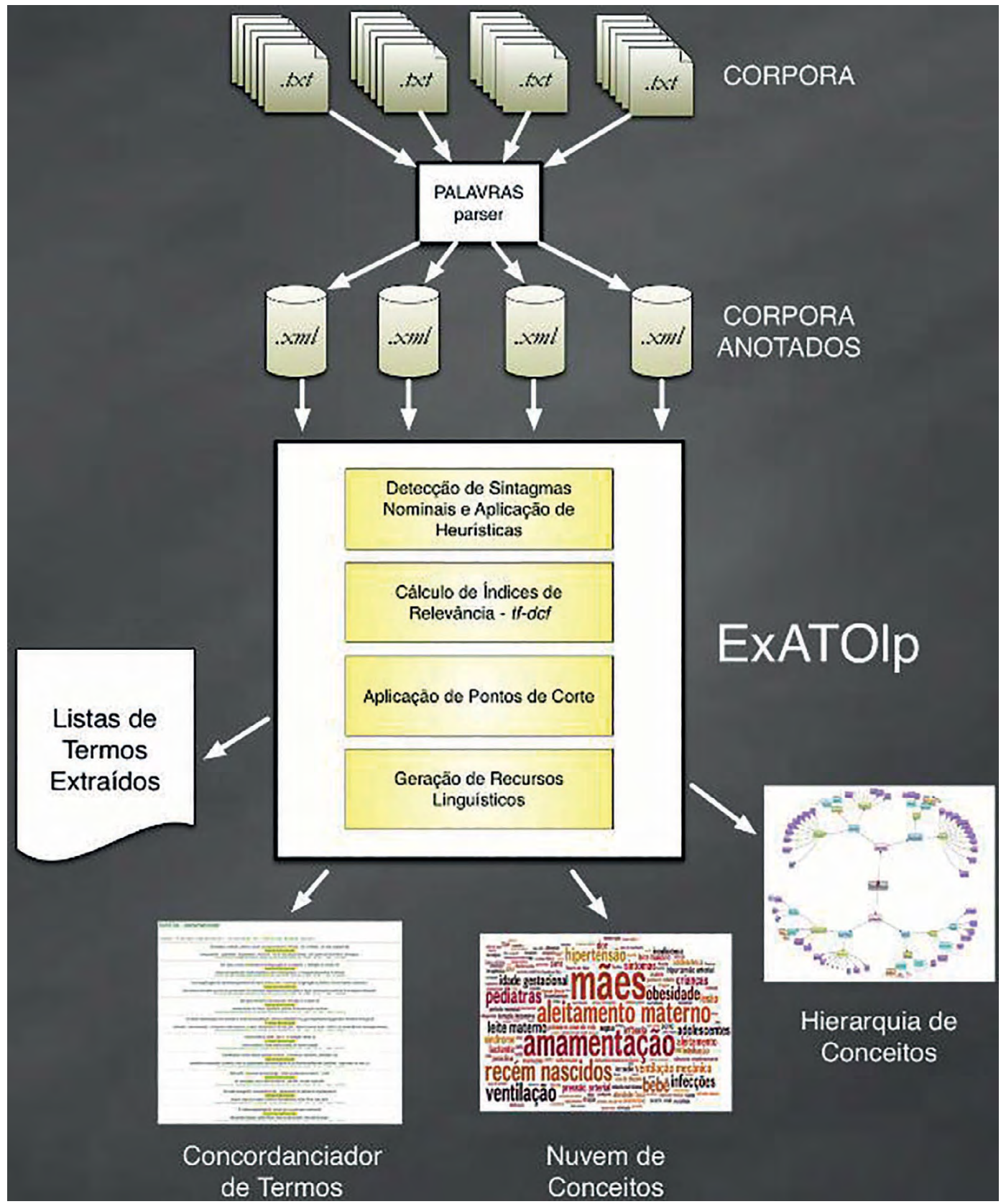

Fonte: Ciulla (2014). 
Os resultados, com as listas dos principais candidatos a termo, podem ser representados em nuvens, em árvores, em concordanciamento ${ }^{3}$ (cotexto imediatamente anterior e posterior) ou podem simplesmente ser uma enumeração de expressões uma abaixo da outra, em ordem decrescente de relevância, conforme os cálculos realizados pela ferramenta. Observamos que, para a área de Processamento de Linguagem Natural, "termo" equivale a "conceito", por isso as expressões "nuvem de conceitos" e "hierarquia de conceitos" aparecem para identificar as listas em nuvens e árvores, respectivamente, no diagrama da Figura 1.

Quanto ao corpus de contraste, a escolha feita para o estudo que apresentamos neste artigo foi a de um corpus de textos de jornais, para que se sobressaíssem termos relacionados à área especializada em contraposição aos da língua em sua modalidade mais cotidiana.

Contudo, um primeiro aspecto a ser considerado é o de que, mudando o corpus de contraste, podem mudar os resultados da ferramenta: o que o corpus de estudo têm em comum com um contraste, não é sempre o mesmo do que com outros conjuntos de textos. Um dos riscos desse método é que ele dá margem para que termos relevantes fiquem de fora - no caso, por exemplo, de eles aparecerem também frequentemente no corpus de contraste, ainda que com significações diferentes.
Outro problema em assim calcular a lista de candidatos a termo é que se arrisca, por exemplo, a deixar de fora homônimos que podem ser termos para um domínio e para outro não, pois a máquina considera apenas a palavra de forma fixa e não as diversas possibilidades de significação que ela pode assumir em diferentes contextos. ${ }^{4}$

Ainda uma terceira questão observada é que a ferramenta opera com uma margem de erro para a análise sintática e morfológica das palavras, o que pode ocasionar tanto a exclusão de algum nome (núcleo de um $\mathrm{SN}$ ) que tenha sido classificado como outro tipo de palavra, como a inclusão de alguma palavra que não seja um nome, mas que, na interpretação da máquina, apresente ambiguidade no que tange às características sintáticas e morfológicas, como pode acontecer com um advérbio, por exemplo.

Além disso, a seleção prévia, pela posição sintática, não garante reunir todos os potenciais candidatos por outro motivo: sabemos que um humano identifica um termo pela sua significação em um texto, que é atribuída por um conjunto de fatores, inclusive sintáticos - mas não apenas. Seria preciso, então, empreender mais estudos, para investigar e fortalecer a hipótese de que termos importantes de uma área de domínio aparecem predominantemente, em um texto, na posição de sujeito e objeto.

Assim, reafirmamos o posicionamento de que quaisquer que sejam os resul- 
tados oferecidos por uma metodologia estatístico-matemática, é preciso sempre voltar ao texto e verificar qual o papel dos termos extraídos em seu habitat de origem, qual seja, o de oposição e contiguidade com todos os outros elementos discursivos que nos permitem atribuir sentido ao texto.

$\mathrm{E}$, por tudo isso, então, não nos fechamos em nossa posição sobre os resultados do ExATOlp. Esse achado apenas sinaliza na direção de uma interpretação. Cada um desses termos elencados pela ferramenta merece ser exaustivamente investigado em sua contextualização no $C L G$ ou em qualquer fonte manuscrita de Saussure.

\section{Análise e resultados: nas nuvens...}

Em estudo recente (CIULLA; FINATTO; LOPES, 2015a), avaliou-se o desempenho do ExATOlp para o texto do $C L G$ com a expectativa de encontrar no topo das listas termos relacionados aos conceitos mais difundidos do legado saussuriano. No entanto, chamou-nos atenção o fato de que, entre os primeiros vinte termos das listas, a maior parte era relacionada a aspectos fônicos.

Dentre os diversos formatos de listas que a ferramenta oferece, escolhemos as nuvens, em que se pode facilmente visualizar os principais resultados, como na Figura 2, a seguir:

Figura 2 - Visualização da nuvem de candidatos a termos do CLG, extraída pelo ExATOlp, com os $\mathrm{SN}$ mais relevantes em letras maiores

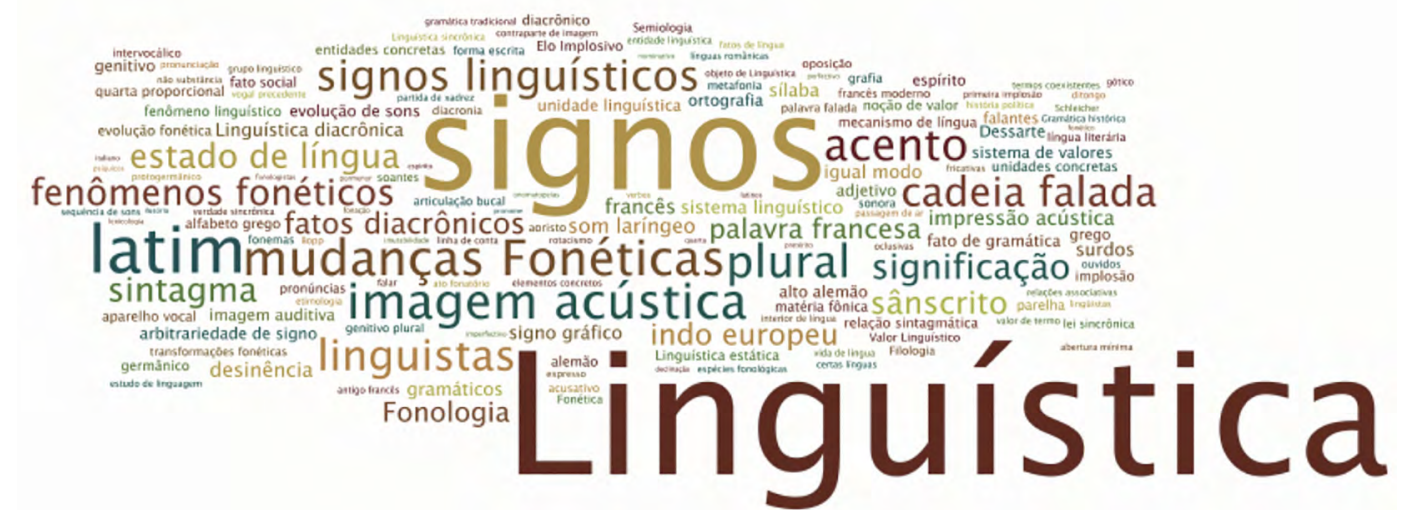

Fonte: Ciulla (2014).

Os termos que aparecem como mais frequentes são signos e Linguística, mas logo a seguir e em maior número, observam-se vários termos relacionados ao fônico, como: mudanças fonéticas, imagem acústica, fenômenos fonéticos, acento, cadeia falada, fonologia, som laríngeo e matéria fônica. É importante destacar que esta primeira nuvem inclui o conjunto de termos mais frequentes, 
reunindo uni, bi e trigramas na mesma análise.

O realizado pela ferramenta provocou-nos uma interrogação acerca da função que o aspecto fônico da língua cumpre na organização das ideias do mestre. Não estariam essas ocorrências concentradas nos capítulos iniciais dedicados à fonologia? Veremos adiante (seção 4) que os resultados do levantamento realizado pelo ExATOlp demonstram que os termos ligados ao fônico estão distribuídos ao longo da obra.

Outra observação importante é a abundância de termos relacionados à diversidade de línguas: palavra francesa, francês, indo europeu, sânscrito, alto alemão, grego. Sobre essas ocorrências, uma das possíveis explicações pode ser a de que Saussure, recorrentemente, no $C L G$, lança mão de seus conhecimentos de línguas, com suas diferentes realizações fônicas, para explicar fenômenos de língua em exemplos de fala. É o que se pode confirmar em diversas páginas ao longo da obra, em que se vê exemplos do francês (p. 37), alemão (p. 34), inglês (p. 38), grego (p. 8), latim (p. 249), sânscrito (p. 44), indo europeu (p. 183), tcheco (p. 215) - aqui apenas citando alguns, a título de ilustração.

E conforme Saussure próprio teria dito:

Depois de ter analisado um número suficiente de cadeias faladas pertencentes a diversas línguas, chega-se a conhecer e a classificar os elementos com as quais elas operam (SAUSSURE, 1974, p. 51).
Vemos, então, que Saussure não apenas lança os fundamentos de um estudo teórico da língua, enquanto sistema, mas simultaneamente recorre às próprias línguas em atividade, para explicar-lhes o funcionamento e, assim, suscitar hipóteses, fornecer insights e explicações sobre o funcionamento da língua de maneira geral. Entendemos aí o fônico como suporte que auxilia o linguista a constatar fatos de língua a partir de fenômenos que são evidenciados na fala.

A ocorrência de termos relacionados a diversas línguas, está, então, estreitamente relacionada à realização fônica das línguas, se não na maior, em grande parte das vezes. Essa é uma hipótese a ser investigada em trabalhos futuros e que reforça a importância do fônico para o estudo do funcionamento da língua. Faz-se importante salientar que tal hipótese foi levantada conjuntamente pelo destaque aos termos revelado pelo ExATOlp, no resultado visual das nuvens, $\mathrm{e}$ pela leitura que se faz desses termos no corpo do texto do $C L G$.

$\mathrm{Na}$ Figura 3, de nuvem em unigramas, o termo que aparece como mais relevante é Linguística, seguido de signos, para logo em seguida mostrar, entre outros, latim, acento e depois sânscrito, Fonologia, francês, surdos, sílaba, grego, alemão e germânico. O que se vê aqui é também uma abundância de termos que se relacionam com o fônico em saliência: 
Figura 3 - Visualização da nuvem de unigramas mais relevantes do CLG, de acordo com o ExATOlp

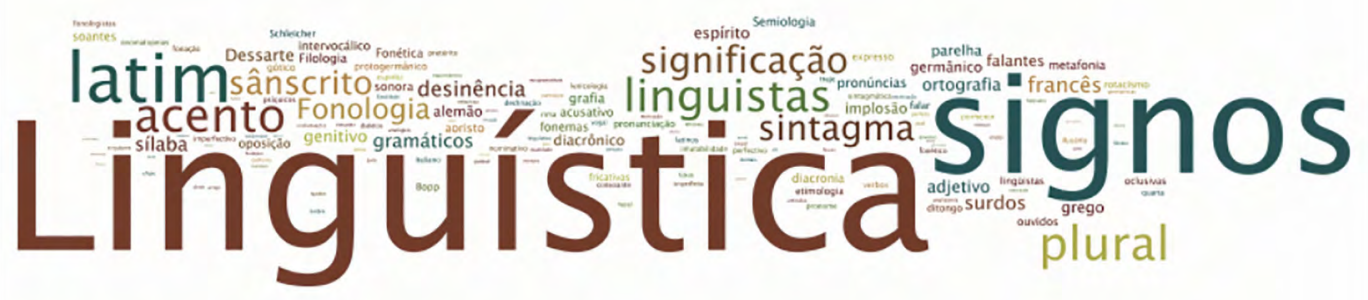

Fonte: Ciulla (2014).

Na Figura 4, apresentamos as nuvens de termos compostos. Conforme Ciulla, Finatto e Lopes (2015a), a combinação de termos simples em compostos concede especificidade ao conceito, caracterizando o SN como termo. Além disso, de acordo com as autoras, há uma tendência de que termos compostos sejam mais frequentes em textos especializados - essa é uma hipótese a ser confirmada, em trabalhos futuros, incluindo-se um estudo com base no $C L G$.

Figura 4 - Visualização da nuvem de bigramas mais relevantes do CLG, extraída pelo ExATOlp

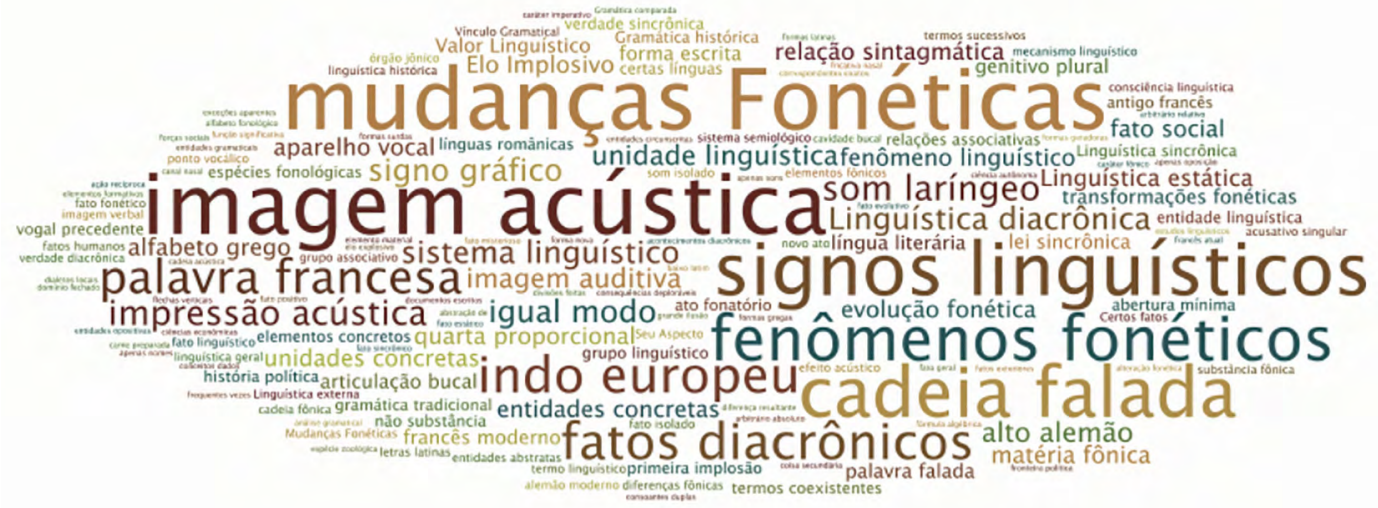

Fonte: Ciulla (2014).

A visualização da nuvem de bigramas reitera o que foi dito acima: o valor do termo composto, especialmente o que é composto por duas palavras, recorta uma especificidade do campo da linguística. Ocorrências como signo linguístico, imagem acústica, cadeia falada, linguís- tica diacrônica e relações sintagmáticas remetem a conceitos importantes na edificação do pensamento saussuriano.

A seguir, nas Figuras 5 e 6, outras imagens, resultantes do processamento pelo ExATOlp: 
Figura 5 - Visualização da nuvem de trigramas mais relevantes do CLG, extraída pelo ExATOlp

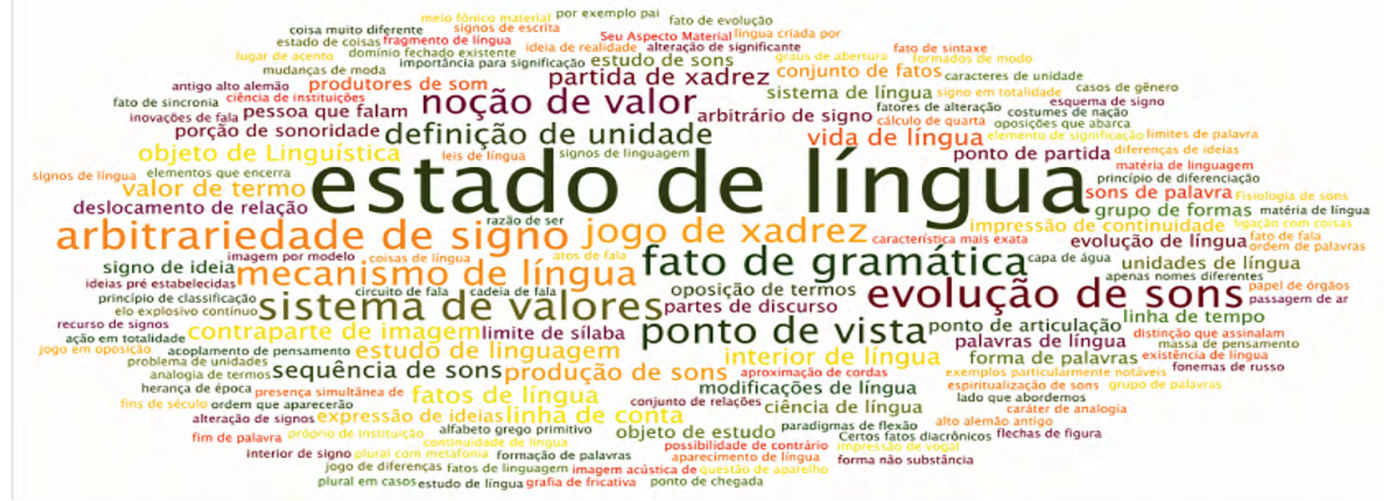

Fonte: Ciulla (2014).

Percebe-se, também nos trigramas, a relevância de palavras relacionadas ao fônico na língua, pela saliência, nas nuvens, de expressões, como: evolução de sons, sequência de sons, produtores de som, produção de sons, pessoas que falam, porção de sonoridade, sons de palavra, grafia de fricativa, fonemas do russo, ponto de articulação, limite da sílaba.

Figura 6 - Visualização da nuvem de quadrigramas mais relevantes do CLG, extraída pelo ExATOlp

cadeia falada em sílabas moeda que fixa valoridêntico estado de coisas dado estado de língua não coincidência com resto

termos reais de sistema porcão acustica soma de signos distintivos porção acustica para ideia oposiçöes dentro de sistema vantagem de ser concreta palavras que exprimem ideias ôa aspecto paradoxal de questão jogo de diferenças fônicas apenas metade de importância aspecto paradoxal de questano diferenças sem termos

imagem acústica com conceito signos que é escrita ciência de instituiçöes políticas forma própria para futuro condiçöes que formaram estado coisa positiva em ordemalteração dé signos linguísticos

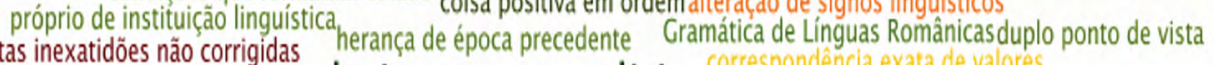
certas inexatidöes näo corrigidas de imagem auditiva princípio de diferenciação formulado
contraparte de aspectos diversos de fatosistema de o qual sistema de valores purosgramática tradicional de francês definição de unidade linguística radical coincidente com oposiçäocaráter a
verdade em relação significante somente diferença de signos oposiçōes de gênero diferencas maior parte de ciências ponto de vista pancrônico questão de aparelho vocal delimitações reciprocas de unidades domínio fechado existente próprio cálculo de quarta proporcional signos acústicos com divisões divisōes tradicionais de Gramática ponto de vista positivovalor de palavra propriedade lingua frente a pensamento sistema dito comumente fonético quase unidades dẹ língua fator historico de transmissẫo aproximação de cordas vocais palavras que podem opor única razäo de sersérie de palavras análogas número determinado
formados de modo idêntico parte conceitual de valor leis estranhas a função baixo ou alto relevo

Fonte: Ciulla (2014). 
Novamente, a presença do som nas nuvens salta aos olhos, em sequências como: contraparte de imagem acústica, jogos de diferenças fônicas, signos acústicos com divisões, porção acústica para ideia, sistema de elementos sonoros, sistema dito comumente fonético, aproximação de cordas vocais.

Observamos que, nas nuvens de tri e quadrigramas, poucos bons candidatos a termos podem efetivamente ser identificados, algumas das sequências configurando-se apenas como um conjunto de palavras. Contudo, mesmo nesses casos, pela frequência de palavras relacionadas aos sons das línguas, há o indício da importância do assunto para a obra, reiterando, assim, o que foi verificado nas listas de uni, bi e n-gramas.

Esse voo panorâmico inicial possibilitou-nos a visualização de nuvens de sons no clássico livro Curso de Linguística Geral. Cabe-nos agora acompanhar os respingos do fônico espalhados ao longo da obra do mestre genebrino. Conforme segue, começam a chover sons das nuvens...

\section{Fundamentação teórica: um percurso no fônico no $C L G$}

Sabemos que há capítulos no $C L G$ explicitamente voltados ao estudo do fônico. O último capítulo da "Introdução" (Capítulo VII) tem como título "A Fonologia” e, em seguida, encontra-se um apêndice intitulado "Princípios de Fonologia”, composto por mais dois capí- tulos: "As espécies fonológicas" (Capítulo I do "Apêndice") e "O fonema na cadeia falada" (Capítulo II do "Apêndice"). Certamente esses capítulos concentram vários dos achados da busca realizada pela ferramenta ExATOlp. No entanto, percebemos que muitos dos termos ligados ao fônico que encontramos dilatados por meio do levantamento não estão exclusivamente localizados nesses capítulos.

Essa constatação incitou-nos a retornar ao texto do $C L G$ com uma indagação de repercussão mais ampla. Se os resultados do levantamento demonstram uma saliência dos termos ligados ao aspecto fônico da língua, o que nos indica essa dilatação para a construção das ideias saussurianas apresentadas ao longo da obra? Obviamente, a partir de agora não estamos mais no terreno da constatação. Afetadas que fomos pelos resultados da consulta informatizada, buscaremos refletir sobre a importância desse achado. O que se segue em nossas observações e comentários não é mais de caráter objetivo. Passamos, então, à nossa interpretação dos achados.

Ao procurarmos rastros sobre o fônico da língua registrados no $C L G$, revisitamos importantes pressupostos-base da teoria saussuriana. Conforme já mencionado em Milano (2015), Saussure deixa importantes pistas sobre o fônico em diferentes documentos. Seus estudos históricos-comparativos dos tempos de Leipzig 5 registram isso. O Mémoire (SAUSSURE, 2009), por exemplo, é 
ancorado em análises da alternância de emprego das vogais em indo-europeu. É também nessa publicação inaugural de Saussure que aparece já o registro do termo fonema. Igualmente seus estudos sobre os anagramas (SAUSSURE, 2013), os trabalhos sobre a acentuação do lituano (SAUSSURE, 2003), os manuscritos Phonétique (SAUSSURE, 1995) e das Sonantes (SAUSSURE, 2002) e os Escritos de Linguística Geral/De la double essence du langage (SAUSSURE, 2004, 2011) indicam uma especial atenção para $\mathrm{o}$ aspecto fônico da(s) língua(s).

Inicialmente, no que diz respeito ao texto do $C L G$, gostaríamos de destacar a presença de termos sobre o fônico nos conhecidos capítulos sobre signo e valor. Ao circunscrever a noção de unidade (signo), o texto apresenta uma significativa valorização do efeito acústico produzido pela diferença entre essas unidades dentro do sistema. Ou seja, a consideração do aspecto fônico indica ser um elemento constitutivo do empreendimento metodológico (e didático) do genebrino para viabilizar a configuração e análise das unidades que compõem o sistema.

Evidentemente, afirmamos que o significante é dependente do aspecto fônico porque está contido nele, ao mesmo tempo, um princípio representacional. Afinal, o fônico funciona como concretude, um "invólucro material" (SAUSSURE, 1974, p. 164). O que garante sua eficácia enquanto unidade do sistema é sua função diferenciadora. Por isso, não nos causa surpresa encontrarmos no capítulo
O valor linguístico a consideração do som dentro do sistema, pois "[...] os fonemas são, antes de tudo, entidades opositivas, relativas e negativas [...]" (SAUSSURE, 1974, p. 138). Vemos nessa passagem um significativo registro do lugar do fônico na lógica pautada pela teoria do valor.

Mas é importante lembrar que subjaz a essa ideia o fato de que o significante é simultaneamente fônico e não fônico. Ou seja, não se trata da consideração do som em si mesmo, mas do som como portador de uma distintividade, conforme mencionamos acima. Afinal, como está registrado no $C L G$, "[...] o que haja de ideia ou de matéria fônica num signo importa menos que o que existe ao redor dele nos outros signos [...]" (SAUSSURE, 1974, p. 139). Insistimos que o caráter paradoxal da marca do fônico é garantir contrastes na língua. O desafio do linguista será lidar de maneira ao mesmo tempo concreta e abstrata com esse fato.

As consequências dessa proposição saussuriana percebe-se, por exemplo, no Apêndice Princípios de Fonologia:

Por aí se vê a importância que a fonologia dos grupos deve ter para a Linguística Geral. Enquanto os fonólogos se limitam geralmente a dar regras para articular todos os sons, elementos variáveis e acidentais das línguas, essa Fonologia combinatória circunscreve as possibilidades e fixa as relações constantes dos fonemas interdependentes (SAUSSURE, 1974, p. 64).

Essa passagem nos apresenta uma constatação extremamente significativa. Muito além de caracterizar a realização de cada um dos sons e propor uma forma de classificação desses, o apêndice nos 
fala de uma fonologia combinatória. Vemos aí um exemplo de situação em que $o$ aspecto fônico da língua serve de pano de fundo para Saussure formular seus princípios teóricos (no caso específico, o conjunto dos sons das línguas como terreno para pôr à prova o valor linguístico).

Proliferam ao longo do $C L G$ passagens em que o fônico cumpre essa função. No entanto, não temos a pretensão de ser exaustivas nos apontamentos, isso demandaria uma investigação detalhada em todo o livro. Nosso objetivo é apenas ilustrar diferentes passagens da obra em que a referência ao fônico se mostra presente. Queremos, com isso, não apenas confirmar os achados apresentados pela ferramenta como também conferir sua função na construção das ideias desenvolvidas pelo genebrino.

Por esse motivo, atentaremos para outras passagens do $C L G$ que não necessariamente são elencadas em um estudo inicial da obra. Referimo-nos à Terceira, Quarta e Quinta Partes do livro, respectivamente, Linguística Diacrônica, Linguística Geográfica e Questões de Linguística Retrospectiva. Nessa segunda metade do $C L G$, encontraremos inúmeras passagens que fazem referência ao fônico, pelo viés da fonética. Deve-se lembrar que o termo fonética era utilizado por Saussure para evocar os estudos da evolução histórica dos sons das línguas. Trata-se, portanto, de uma abordagem diacrônica do aspecto fônico das línguas.
Por exemplo, na Terceira Parte, aquela dedicada à Linguística Diacrônica, encontraremos repetidas referências ao sons das línguas - os fonemas - quando se trata de definir o objeto do estudo:
A Fonética e toda a Fonética, constitui o pri- meiro objeto de Linguística diacrônica; com efeito, a evolução dos sons é incompatível com a noção de estado; comparar fonemas ou grupos de fonemas com o que foram anteriormente equivale a estabelecer uma diacronia (SAUSSURE, 1974, p. 163-164).

Novamente nos chama atenção o fato de a materialidade fônica da mudança fonética ser organizadora da delimitação do próprio campo dos estudos diacrônicos. Bem sabemos que integram também essa reflexão noções importantes referidas nas seções sobre analogia, etimologia e aglutinação. Mas não nos parece detalhe a evolução fonética ser um tema realmente decisivo para o estabelecimento metodológico proposto por Saussure. Não é na realização fônica em si que a significação e o valor se constituirão, mas por se aliarem a materialidades desde as quais evidencia-se o jogo de diferenças e oposições próprio a cada língua. Por esse motivo, entendemos que: 1. Mudanças fonéticas podem ou não afetar o sistema, pois isso dependerá do fato de essa mudança produzir ou não novo valor linguístico; 2 . Mudanças fonéticas são fatos diacrônicos entendidos em total dependência de uma dada sincronia, afinal, "nada entra na língua sem ter sido antes experimentado na fala" (SAUSSURE, 1974, p. 196). Isso confirma o que já apontamos em relação 
ao método sincrônico, pois muito mais do que propor o estudo pormenorizado e isolado de cada unidade fônica, é a capacidade semiológica que os sons das línguas carregam que interessa verdadeiramente ao linguista.

O fônico se apresenta também na Quarta Parte, onde é tratada a Linguística Geográfica. Ao discutir brilhantemente as forças que agem sobre a língua por meio das imagens de "força de intercurso" e "espírito de campanário", Saussure também recorre ao fônico. A fonética e o fonema serão referenciados para distinguir inovação e empréstimo:

O foneticista distinguirá, pois, cuidadosamente os focos de inovação, em que um fonema evolui unicamente sobre o eixo do tempo, e as áreas de contágio que, relevando simultaneamente do tempo e do espaço, não terão que intervir na teoria dos fatos fonéticos puros (SAUSSURE, 1974, p. 240).

Finalmente, cabe ainda uma palavra sobre a Quinta (e última) Parte do $C L G$. Em Questões de Linguística Retrospectiva, encontramos não raras alusões ao fônico. Destacaremos apenas duas. Ao abordar a reconstrução de línguas antigas, Saussure nos dirá que

[...] para conhecer as unidades fônicas de uma língua, não é indispensável caracterizar-lhes a qualidade positiva; cumpre considerá-las como entidades diferenciais cuja peculiaridade consiste em não se confundirem umas com as outras (SAUSSURE, 1974, p. 258).

Reconhecemos nessa passagem aquilo que já havíamos mencionado, ao darmos destaque ao apêndice Princípios de Fonologia. É no contexto de uma fonologia combinatória que se pode estudar a função dos sons em um estado de língua. Tudo indica que as hipóteses sobre a função do $a$ no indo-europeu (tema abordado no Mémoire) já anunciavam o embrião dessa reflexão.

Merece também nossa atenção o rastro do fônico deixado no filtro da ferramenta ao marcar a relevância do termo acento. A citação é um pouco longa, mas o leitor perceberá que ela se justifica.

Considere-se, por exemplo, a família indo-europeia; conhecem-se as características distintivas da língua de que se originou; o sistema de sons é de grande sobriedade; nem grupos complicados de consoantes nem consoantes duplas; um vocalismo monótono, mas que dá lugar a um jogo de alternâncias extremamente regulares e profundamente gramaticais; um acento de altura, que se pode colocar, em princípio, em qualquer uma das sílabas da palavra, e que contribui, por conseguinte, para o jogo das oposições gramaticais; um ritmo quantitativo, que se funda unicamente na oposição de sílabas longas e breves [...]. (SAUSSURE, 1974, p. 268-269).

Mais uma vez nos cabe sublinhar que, também no caso do acento, não se trata do fônico pelo fônico, mas de o acento, ou qualquer outro indício material viabilizado sob forma de uma porção significante, funcionar como portador de diferença.

Enfim, os recortes aqui apresentados servem para mostrar que, para Saussure, o elemento sonoro concreto não aparece nunca sozinho, isolado. Justamente ele alerta que se assim for, não se está mais no terreno da Linguística, mas no da fisiologia da fala (cf. SAUSSURE, 1974, p. 42). 
Nosso estudo buscou apenas investigar o lugar que o fônico ${ }^{6}$ ocupa no percurso de reflexão presente no $C L G$. Se, como nos ensina o genebrino, um signo é o que os outros não são, acreditamos ser necessário buscar uma pista na realidade concreta desse signo para que se possa identificá-lo como pertencente a uma dada língua e opô-lo a todos os demais signos que compõem o sistema. Por ora, cabe reconhecermos que o voo panorâmico permitiu-nos o reencontro com teses fundantes dessa obra centenária a partir da escuta do fônico.

\section{Considerações finais}

Para finalizarmos este artigo, é importante destacar a novidade que nos proporcionou a ferramenta ExATOlp, ao mostrar a saliência dos termos relacionados ao fônico no $C L G$. Essa mudança de ponto de vista, propiciada pelo voo panorâmico, permitiu-nos renovar a leitura que fazemos da obra.

Contudo, reiteramos que o recurso informatizado de extração de dados isoladamente não dá conta da complexidade que o estudo demanda. Será sempre necessário voltar ao texto em questão. É somente na tessitura da obra estudada que se pode depreender uma interpretação consistente dos resultados encontrados. Nesse sentido, acreditamos ter aproveitado a pista que o rastreio da ferramenta forneceu para constatar a relevância que o aspecto fônico assume no empreendimento teórico-metodológico expresso no $C L G$.
Isso talvez seja o indício de uma porta de entrada para o linguista no campo dos estudos da linguagem. Se a "linguagem é multiforme e heteróclita" (SAUSSURE, 1974, p. 17), várias são as possibilidades para estudá-la, fato que leva o mestre a falar na adoção de diferentes pontos de vista. Dos múltiplos sistemas simbólicos que o homem tem à sua disposição, a língua é apenas o mais recorrente. Acreditamos que, para ter acesso à língua, o linguista não pode prescindir da materialidade da fala. Tudo indica que Saussure, em suas aulas, ao recorrer com frequência a exemplos em várias línguas do mundo, apontava que a tarefa do linguista de propor um estudo sistemático da língua inevitavelmente passa pelo aspecto fônico. Ou seja, é a materialidade fônica da cadeia falada que permite ao linguista a construção de conceitos abstratos para o próprio campo.

As nuvens trouxeram à tona dados que talvez passassem despercebidos até ao leitor iniciado, já que ele supõe de antemão uma rede conceitual própria ao pensamento saussuriano. Mas qual não foi a surpresa de encontrar termos não previstos ou bem menos recorrentes nas interpretações vigentes do $C L G$ ! Que outros pesquisadores possam também se surpreender com instigantes elementos que estejam nas nuvens; essa foi a leitura que ora nos tocou empreender. 


\section{Sounds in the clouds: about the place of the phonic in the Course in General Linguistics}

\section{Abstract}

In this article, we start from a reading of the Course in General Linguistics, with the support of automated resources. Through the computational perspective, our proposal is to simulate a free reading, as far as possible, of that important work, whose interpretations in most cases are linked to tradition already established by classical studies. However, this exercise of objectivity - or attempt to move away from canonical readings - only allows us to raise questions about some aspects of the interpretation of the book. We must always go back to the text and to our role as readers, investigating thoroughly each one of those hypotheses. According to the results provided by the tool, the most relevant terms of the $C L G$ are related to a theme minimized by most Saussurian studies: the phonic system of languages. Our aim then was to establish a connection between that result, which points to a great importance of the phonic in languages, and what it can be apprehended from the Genevan master's work.

Keywords: Phonic. Course in General Linguistics. Ferdinand de Saussure.

\section{Notas}

Análises do CLG via ExATOlp já foram realizadas em trabalhos anteriores, em Ciulla, Finatto e Lopes (2015a; 2015b) e em Ciulla e Finatto (2013), apresentando, contudo, enfoques diferentes do que trazemos neste artigo.
2 Tipo de aeronave não tripulada, mas comandada por seres humanos à distância e frequentemente equipada com câmeras para captação de imagens aéreas: imagem que se presta bem, aqui, para representar a nossa ferramenta computacional de extração de termos.

3 Termo utilizado pela Linguística de Corpus e no Processamento Natural da Linguagem; são trechos localizados por uma ferramenta automática, contendo o cotexto imediatamente anterior e posterior ao termo em questão, na busca.

4 Por exemplo, uma mesma palavra pode ter um sentido comum no corpus de contraste, mas assumir o valor de termo no corpus de estudo.

$5 \quad$ Mémoire sur le système primitif des voyelles dans les langues indo-européenne (1879) e De l'emploi du génitif absolu en sanskrit (1881).

6 Cabe lembrar que a consideração do aspecto fônico da língua no legado de Ferdinand de Saussure também foi foco do interesse de Badir (2012), Coursil (2000, 2015), Parret (2002, 2014) e Marchese (1995, 2009).

\section{Referências}

BADIR, Sémir. Le concret et l'abstrait dans la phonologie et dans la phonetique de Saussure. Cahiers Ferdinand de Saussure, Genève, v. 1, n. 65, p. 13-23, 2012.

CIULLA, Alena. Recuperação da informação em representação do conhecimento em bases de textos científicos de Linguística e de Medicina: padrões de processamento automático da linguagem. $3^{\circ}$ Relatório parcial do Projeto DOCFIX-Fapergs/Capes. Porto Alegre: UFRGS, 2014.

CIULLA, Alena; FINATTO, Maria José Bocorny; LOPES, Lucelene. Extração automática de candidatos a termos do Curso de Linguística Geral via enfoques da Linguística de Corpus e do Processamento de Linguagem Natural. Domínios de Lingu@Gem, Uberlândia, v. 9, p. 41-59, 2015a.

. O CLG como corpus linguístico em português: representação de conhecimento e questões de tradução. In: Clemilton Lopes Pinheiro; Maria Hozanete Alves de Lima 
(Org.). Diálogos: Saussure e os estudos linguísticos contemporâneos. Natal: EdUFRN, 2015b, v. 2, p. 45-65.

CIULLA, Alena; FINATTO, Maria José Bocorny. O signo linguístico em Saussure: algumas questões sobre a tradução para o português brasileiro. Traduzires, Brasília, v. 2, p. 55-64, 2013.

COURSIL, Jacques. La fonction muette $d u$ langage. Guyane Française: Ibis Rouge, 2000.

. Valeurs pures: le paradigm sémiotique de Ferdinand de Saussure. Limonges: Lambert-Lucas, 2015.

LOPES, Lucelene. Extração automática de conceitos a partir de textos em língua portuguesa. 2012. 113f. Tese (Doutorado em Ciência da Computação) - Faculdade de Informática, Pontifícia Universidade Católica do Rio Grande do Sul, Porto Alegre, 2012.

MARCHESE, Maria Pia. Les manuscrits saussuriens sur la phonétique, du Mémoire au Cours de linguistique générale. Cahiers Ferdinand de Saussure, Genève, v. 1, n. 62, p. 47-61, 2009.

Introduzione. In: SAUSSURE, F. Phonétique: Il manoscritto di Harvard. Houghton Library, edizione a cura de Maria Pia Marchese, Università degli studi di Firenze. Padoue : Unipress, 1995.

MILANO, Luiza. Fonético e fonológico em Saussure: o lugar do fônico no Curso de Linguística Geral. Eutomia, v. 1, n. 16, p. 245-258, 2015.

PARRET, Herman. La voix et son temps. Bruxelas, Bélgica: De Boeck \& Larcier, 2002.

Le son et l'oreille: six essais sur les manuscritos saussureins de Harvard. Paris: Lambert-Lucas, 2014.

SAUSSURE, Ferdinand de. Curso de Linguística Geral. São Paulo: Cultrix, 1974.
Escritos de Linguística Geral. (Organizados e editados por Simon Bouquet e Rudolf Engler). São Paulo: Cultrix, 2004.

. Science du langage : De la double essence du langage et autres documents du ms. BGE Arch. de Saussure 372. Édition critique partielle mais raisonnée et augmentée des Écrits de linguistique générale. (Édité par René Amacker). Genève : Droz, 2011.

. Anagrammes homériques. (Présentés et édités par Pierre-Yves Testenoire). Paris: Lambert-Lucas, 2013.

Mémoire sur le système primitif des voyelles dans les langues indo-européenne. New York: Cambridge University Press, 2009.

Phonétique. Il manoscritto di Harvard. Houghton Library, edizione a cura de Maria Pia Marchese, Università degli studi di Firenze. Padoue : Unipress, 1995.

Théorie des sonantes : Il moanoscritto di Geneva. Edizione a cura de Maria Pia Marchese, Università degli studi di Firenze. Padoue : Unipress, 2002.

. Notes sur l'accentuation lituanienne. L'Herne Saussure. Paris : Ediktions de l'Herne, 2003. 